\title{
COMPRENSIÓN LECTORA Y TEXTOS LITERARIOS: UNA PROPUESTA PSICOPEDAGÓGICA
}

\author{
Silvia Méndez Anchía \\ Profesora investigadora \\ del Instituto de Investigaciones Psicológicas \\ de la Universidad de Costa Rica.
}

Recibido 01-II-2005

- Aceptado 25-IV-2006

\begin{abstract}
Resumen: El ensayo presenta una reflexión sobre la lectura de textos literarios en el tercer ciclo de la Enseñanza General Básica en relación con el fomento de la comprensión lectora y la formación del estudiantado. Primero, se realiza una breve presentación de los programas de estudio de Español del Ministerio de Educación Pública en lo relativo a la lectura de textos literarios. Luego se aclaran dos premisas de la propuesta: la concepción de Psicopedagogía que le sirve de encuadre y el orden de presentación de los niveles de lectura. Se desarrollan, a continuación, una serie de consideraciones acerca de los seis niveles de comprensión lectora propuestos en los programas de estudio (literal, de reorganización de lo explícito, inferencial, evaluativo, apreciativo, y aplicativo $y$ recreativo) con base en las demandas cognitivas que implica la lectura de textos literarios, para plantear, por último, la necesidad de que la lectura forme $y$ transforme a los sujetos adolescentes.
\end{abstract}

Palabras clave: Español, enseñanza media, comprensión lectora, literatura, psicopedagogía.

\section{Introducción}

En la sociedad de la información, la tarea educativa se debe orientar hacia un enseñar a aprender. Una de las principales habilidades para lograr esta meta radica en la comprensión lectora, y uno de los materiales más ricos para desarrollar esta capacidad se encuentra en los textos literarios.

Acorde con las demandas de autoaprendizaje que plantea la sociedad actual, los programas de estudio de Español del Ministerio de Educación Pública de Costa Rica enfatizan en la lectura como capacidad fundamental para el desarrollo del estudiante. Se presentan seis niveles de comprensión lectora - literal o explícito, de reorganización de lo explícito, inferencial o figurativo, de evaluación, de apreciación, y de aplicabilidad y recreación-, con base en los cuales es posible trabajar con diferentes textos, a efectos de promover las habilidades del alumnado. Esta forma de plantear la comprensión tiene como fin evitar una visión reduccionista de la lectura que la limita a la literalidad; asimismo, trae consigo una recomendación metodológica para trabajar la comprensión de lectura mediante guías que fomenten esta habilidad de una 


\begin{abstract}
The essay presents an insight on the reading of literary texts in the Third Level General Basic Education in relation with the text students' understanding of the text and their academic achievement in general. First, a short presentation of the guidelines for reading comprehension of the Spanish study programs from the Ministry of Education is given. Next, two concepts are discussed: the psychopedagogical concept that works as the baseline, and the order of the different levels of reading. Then, a series of considerations about the six levels of reading comprehension proposed by the Ministry of Education are developed (literal, reorganization of the explicit, inferential, evaluative, appreciative, applicative, and recreational). The considerations are based on the demands for knowledge implied in the reading of literature texts. Finally, the role of reading in the adolescents' academic achievement and behavior modification is discussed.
\end{abstract}

Key words: Spanish, secondary education, reading comprehension, literature, psychopedagogy. manera integral. Así lo plantean Sánchez, Rojas y Víquez (1997, pp. 8-9):

"Lo que necesitan las alumnas y los alumnos es la posibilidad de contar con buenos y agradables textos que despierten su interés y guías de lecturas que sean capaces de ejercitar todas sus capacidades mentales. Por lo tanto a la hora de orientar el proceso se deben tomar en consideración los niveles para construir guías de lectura o propuestas de lectura; que contemplen la totalidad del texto y no únicamente el nivel literal."

Ahora bien, ¿qué sucede cuando, en el tercer ciclo, se trabaja con textos literarios? ¿Las lecciones de literatura fomentan la comprensión lectora en sus diversos niveles? Y, de ser así, ¿es posible trascender, mediante la lectura de textos literarios, ese ámbito de habilidades para alcanzar el desarrollo de lo que Françoise Dolto (1997) ha llamado la "inteligencia en la realidad"? Estas interrogantes dirigen la propuesta que se plantea en este ensayo. Pero antes de entrar al análisis de estos puntos, se realiza una breve presentación de las características de los programas de estudio de Español del Ministerio de Educación Pública en lo relativo a la lectura de textos literarios en el tercer ciclo de la Enseñanza General Básica.

Los contenidos relacionados con la literatura en el tercer ciclo se basan en categorías que proceden de los estudios literarios, en una clara correspondencia con un currículo de corte academicista, entendido como aquel cuyos objetivos "enfatizan en el logro de conocimientos provenientes de la cultura sistematizada" (Bolaños y Molina, 1990 , p. 93). Por ejemplo, las siguientes son las categorías que se señalan para el estudio de la narrativa, en el programa de Español de sétimo año:

"Lectura de textos literarios

Cuento, Novela, Leyenda y Crónica.

- Análisis de los siguientes elementos:

Narrador: Tipos (omnisciente, testigo y protagonista); visiones (narrador $>$ personajes, narrador $<$ personajes, narrador $=$ personajes); organización secuencial de la historia narrada (lineal o perturbada); código 
apreciativo (valoración de las partes del mundo mostrado); registros del habla (lenguaje culto, coloquial, técnico, literario); los estilos directo e indirecto, planos.

- Mundo mostrado: espacios (físico, ético, religioso, jurídico, educativo, económico, político, social, ecológico o psicológico, cuando los haya); personajes (lo que dicen ser y lo que hacen), su interacción con los otros, su código apreciativo (valoración del mundo mostrado).

- Relaciones del texto con el contexto sociocultural, con los géneros y los movimientos literarios." (CR, MEP, 2005)

Esta forma de plantear los contenidos de la lectura literaria puede llevar a los docentes a inclinarse más por un análisis estricto de ciertas categorías presentes en las obras, que por la promoción de la totalidad de los procesos lectores que se activan en el estudiante al entrar en contacto con los textos.

Si, en la práctica del aula, estas categorías de análisis procedentes de los estudios literarios no se contextualizan en un plan de desarrollo integral de habilidades lectoras, su estudio con los alumnos resultará árido y, en algunos casos, no significativo para estos.

Una aplicación del programa de estudios que no contemple, de manera integral, la promoción de estrategias de comprensión lectora para el trabajo con textos literarios, puede terminar en una desafortunada estructuración que se impone rígidamente a todas las obras estudiadas sin considerar su especificidad. Puede incurrirse, así, en el error de supeditar todo a un esquema predeterminado como si, por sobre la significación del texto literario mismo y sobre la pluralidad de lecturas que pueden realizarse a partir de este, el análisis rígido de idénticas categorías para todos los textos pertenecientes a un mismo género actuase como una especie de "lecho de Procusto", donde todo debe calzar, aunque no se amolde. En una investigación anterior, se expusieron las apreciaciones de una docente de Español acerca de esta problemática:
"El análisis que proponen [los programas de estudio] se caracteriza por ser esquemático y homogenizante: '...parecieran haberlos hecho en una plantilla igual para todas las literaturas: autor, yo lírico, tipo de narrador'; la docente critica esta predeterminación de categorías, 'incapaces —escribe ella- de abarcar la esencia de una obra...” (Méndez Anchía, 2000, p. 97)

Con base en estas observaciones, se considera justificado plantear un marco de referencia sobre los procesos lectores en relación con los textos literarios. Este tiene como finalidad favorecer una aproximación psicopedagógica a la literatura, que contemple tanto las categorías de análisis específicas que se proponen en el programa de estudios, como los procesos cognitivos asociados con los distintos niveles de comprensión de lectura que también se citan en dicho programa, y que a la vez plantee la posibilidad de enfatizar en la literatura como formadora de los estudiantes en lo que se refiere a su vida personal y a su comprensión de la realidad circundante.

\section{Encuadre teórico para una aproximación psicopedagógica a la lectura literaria}

En los apartados siguientes se presentan una serie de consideraciones acerca de la comprensión lectora y el estudio de la literatura, con la finalidad de ofrecer, al docente de Español de tercer ciclo de la Enseñanza General Básica, una propuesta psicopedagógica para el trabajo con textos literarios.

Para empezar, es necesario hacer dos aclaraciones: una en relación con el concepto de Psicopedagogía que se está manejando en este ensayo y otra sobre el orden en que se expone la propuesta.

Siguiendo a Marina Müller (2001), se entiende la Psicopedagogía como una disciplina cuyo objeto de estudio es el aprendizaje humano: la manera como las personas aprenden, en este caso a leer literatura; las variaciones evolutivas de ese aprendizaje; 
los diversos factores que lo condicionan; la causa de las alteraciones del aprendizaje, así como su prevención y la búsqueda de procesos de aprendizaje dotados de sentido para los estudiantes. En este caso específico del aprendizaje de la lectura de textos literarios, es necesario que el aporte psicopedagógico se sustente en otras disciplinas como la Teoría Literaria, la Psicología Cognitiva y el Psicoanálisis, con la intención de proponer estrategias de aprendizaje que tomen como eje a los estudiantes sin perder de vista la especificidad del texto literario. Para ello resulta también indispensable rescatar criterios curriculares psicologistas, según los cuales el proceso de aprendizaje debe centrarse en el estudiante y, en cuanto a este tomado como eje, trabajar con las siguientes premisas: “-Interesan los procesos de la persona, sus necesidades, intereses y problemas. -El individuo se percibe como un ser concreto en proceso de formación. -El individuo es activo, dinámico, participativo" (Bolaños y Molina, 1990, p. 93).

La segunda aclaración se relaciona con el orden de la exposición de los procesos lectores. Para efectos de esta propuesta, se plantearán en una forma secuencial, para guardar una coherencia en términos expositivos, yendo de lo simple a lo complejo. Sin embargo, en la práctica, esos niveles de comprensión no están separados ni se dan en un orden estricto e inalterable; todo lo contrario, como señala Goodman (1996), este proceso es complejo, y ya desde el momento mismo de la lectura de datos explícitos, el lector está seleccionando aquellos que le interesan de acuerdo con sus previsiones de sentido. Por tal razón, deben considerarse tanto los procesos cognitivos que se activan al entrar en contacto con la literatura como la especificidad de cada texto, y no apegarse a un orden fijo de niveles de comprensión lectora. Se concuerda, en ese sentido, con lo que sostienen Sánchez, Rojas y Víquez (1997, p. 9):

\footnotetext{
"Desde esa perspectiva, generalmente se introduce la comprensión de lectura a partir de lo explícito, ciertos indicios o marcas de este nivel permiten articular una
}

o varias inferencias, es decir, posibilitan el acceso a lo implícito del texto. Una vez lograda la comprensión de lectura, se puede pasar a los aspectos apreciativos, evaluativos o recreativos. Este es un ordenamiento descriptivo; a la hora de elaborar la guía se presentan ocasiones en que el nivel apreciativo se funde con el implícito o el recreativo para completar la comprensión del texto. No existen recetas fijas y mecánicas, el acto de leer es un acto comunicativo por excelencia y requiere de todas nuestras capacidades. Cada texto tiene su propia dinámica."

\subsection{El nivel de comprensión literal y los procesos denotativos}

El primer nivel de comprensión de lectura es el literal. En este, el lector se ocupa de las ideas expuestas de modo explícito, identificando informaciones tales como personajes, acontecimientos, lugares donde se desarrollan las acciones y el tiempo cuando estas transcurren (CR, MEP, 2005).

Desde una aproximación propia del análisis literario, este nivel corresponde a lo denotativo, paso inicial para la comprensión del texto. En términos bastante simples, la denotación constituye un sentido primario, en el cual los significados de las palabras remiten o se limitan a los que establece el diccionario.

He aquí un señalamiento importante en relación con este nivel: resulta erróneo considerar que el proceso de lectura es mejor en tanto más detalles se recuerden. La lectura es una práctica interactiva, lo cual quiere decir que no parte únicamente del material escrito, cuyo desciframiento y memorización realizaría el lector en forma automática, sino que constituye una labor que se da por dos vías: del texto al lector y del lector al texto.

Así, no se debe olvidar nunca, en el ejercicio docente relativo al desarrollo de habilidades comprensivas, que el lector selecciona aquellos datos que considera relevantes para su propio proceso de lectura. Tal estrategia se conoce como "muestreo" y, según Goodman (1996), se da en función de la utilidad tanto perceptiva como comprensiva; este autor dice lo siguiente: 
"El texto provee índices redundantes que no son igualmente útiles. El lector debe seleccionar de estos índices aquellos que son más útiles. Si los lectores utilizaran todos los índices disponibles, el aparato perceptivo estaría sobrecargado con información innecesaria, inútil o irrelevante.” (p. 21)

Esta selección o "muestreo" de que habla Goodman forma parte de un proceso interactivo, en el que cuentan tanto los caracteres impresos en el texto literario (con su correspondiente significado denotativo) como las expectativas e intereses del lector, quien conforme avanza en su proceso de lectura, va reelaborando el texto en aras de encontrarle sentido. De ello se desprende que no se podrá esperar que todos los estudiantes recuerden los mismos datos acerca del texto leído.

La argumentación anterior invalida algunas pruebas de comprobación de lectura que se realizan en las aulas en las cuales el estudiante tiene que dar cuenta de algún detalle, o de muchos detalles, que no necesariamente consideró dentro de su propio proceso de "muestreo" del texto. Valga un ejemplo para ilustrar este caso, en que se utiliza la prueba de comprobación de una manera que puede conducir, a muchos estudiantes, a aborrecer la lectura: un muchacho de doce años acaba de terminar de leer su primera novela, Marcos Ramírez, y se encuentra muy entusiasmado por las aventuras que narra el personaje; sin embargo, falla en su prueba de comprobación de lectura, pues se le pregunta por el nombre de la madre de Marcos, dato que se cita sólo dos veces, en un texto que supera las trescientas páginas, y que aparece referido no de manera directa, sino por el discurso del tío Zacarías, que dice "¡Hum...! [...] ¡Usté me le dio de comer a ese bandido, Fidelia!" (Fallas, 1995, p. 71), y por el de doña Fortunata, quien le advierte a Marcos lo siguiente: “¿No estás pensando en tu madre...? ¡A estas horas la pobre Fidelia debe andar media loca, buscándote!" (p. 290).

De lo anterior se desprende que la lectura en el nivel literal no resulta tan simple como puede parecer a primera vista, pues depende del proceso particular de "muestreo" efectuado por cada lector, proceso que se inserta en un trabajo de transacción texto-lector. En el apartado siguiente, se expondrá cómo a la etapa inicial de lectura de información explícita se añade la reorganización de esta, como paso previo para el desarrollo de habilidades inferenciales, que se hallan estrechamente relacionadas con la lectura de textos literarios.

\subsection{El nivel de reorganización de lo explícito: paso previo para la interpretación}

Como se ha señalado en el apartado anterior, un aspecto primordial que debe tomarse en cuenta a la hora de trabajar, en el aula, con textos literarios, consiste en el hecho de que todo proceso de lectura se rige por una búsqueda de sentido. Véase lo que, al respecto, señala Goodman (1996, p. 24):

"La búsqueda de significado es la característica más importante del proceso de lectura, y es en el ciclo semántico que todo toma su valor. El significado es construido mientras leemos, pero también es recons truido ya que debemos acomodar continuamente nueva información y adaptar nuestro sentido de significado en formación. [...] La lectura es, pues, un proceso dinámico muy activo. Los lectores utilizan todos sus esquemas conceptuales cuando tratan de comprender."

En otras palabras, el lector trata de ir encontrando un significado conforme va descifrando el mensaje del texto. Su labor es totalizadora: no se detiene en cada detalle que se le presenta, pues ello constituye una labor imposible en términos cognoscitivos. Tal situación se torna más compleja en el caso de la lectura de textos literarios, ya que la pluralidad —entendida como la posibilidad de generar varios significados, en lugar de uno solo- es constitutiva de estos, razón por la cual esa búsqueda de sentido -y el trabajo de "muestreo" asociado con ella- adquiere una mayor cantidad de posibilidades según cada lector que entre en contacto con el texto. 
Aclaradas estas premisas, se expondrá seguidamente lo relativo al segundo nivel de comprensión lectora, denominado de reorganización de lo explícito. Este contempla habilidades tales como el análisis, la síntesis, la esquematización, la paráfrasis y la jerarquización, todas ellas desarrolladas a partir de la información explícita en el texto; además, en lo referente a la lectura de textos literarios, incluye el reconocimiento de las categorías predominantes en cada género, lo mismo que las características de los diversos movimientos (CR, MEP, 2005).

Desde el punto de vista de los textos literarios, constituye un paso previo para la lectura connotativa, es decir, la que se basa en segundos significados, al suponer una serie de habilidades necesarias para organizar las informaciones que darán pie a la formulación de una lectura interpretativa, como son el análisis, la síntesis, la esquematización y la comparación.

Para citar un ejemplo, en este nivel de comprensión el estudiante podría organizar a los personajes de la novela $L a$ loca de Gandoca, de Anacristina Rossi (2001), según los valore positiva o negativamente Daniela, la narradora. Así, el lector procederá, con base en la información explícita, a clasificar a los personajes (Carlos Manuel, Sergei Domeniev, el Ministro, el Viceministro, Ana Luisa, el hombre de los diez bypasses, Álvaro Cienfuegos, Robinson, Wallis Black, el dueño del Monte, Máinor Rojas, Yemanyá, Dominique, Mariana, Margarita y Medea), para luego realizar sus inferencias en torno a lo que ellos representan en relación con el conflicto de la destrucción del Refugio de Gandoca, uno de los grandes temas que podrían interpretarse en este texto.

Nótese que los procesos relacionados con la reorganización de lo explícito deben insertarse en un trabajo de asignación de un sentido posible para el texto literario. Por tal razón, es conveniente que, si se realiza, por ejemplo, una tarea de análisis de un texto, esta conduzca a alguna atribución de significado, es decir, que esté guiada por una hipótesis de lectura.
Ahora bien, el programa de estudios del Ministerio de Educación Pública también hace referencia, en este nivel de reorganización de lo explícito, a las categorías predominantes en cada género y a las características de los diversos movimientos literarios. $\mathrm{Al}$ llegar a este punto, conviene recordar un aspecto que se ha señalado, al inicio de este ensayo, como la preocupación fundamental que lo orienta: se refiere al hecho de que la ausencia de contextualización de las categorías de análisis de procedencia teórico-literaria puede hacer que la lectura resulte árida y carente de significado para los alumnos; si tales categorías se convierten en un "lecho de Procusto", que sirve lo mismo para un texto que para otro, ello puede dar al traste con un trabajo de búsqueda de significado por parte del lector. De lo anterior se derivan dos consideraciones básicas para esta propuesta, a las cuales se hará referencia en los párrafos siguientes.

Primero, una aproximación psicopedagógica a la literatura precisa la aplicación de un enfoque flexible. Tal flexibilidad proviene del texto literario mismo, siempre y cuando se respete la variedad de los textos literarios, lo que cada uno de ellos plantea, así como sus diferencias y sus semejanzas con los otros textos (literarios $y$ culturales en general).

Por ejemplo, en el caso del Romanticismo, dos textos que se estudian como representativos de este movimiento son "La ajorca de oro", de Gustavo Adolfo Bécquer, y la crónica titulada "Las carreras de San Juan", de Manuel de Jesús Jiménez. La idealización de la mujer amada, una característica muy conocida del Romanticismo, aparece con claridad en el texto de Bécquer, mientras que en el de Jiménez este rasgo no se presenta, pero sí predomina el gusto por el pasado, característica en la cual coinciden ambos textos. Estas diferencias y semejanzas, que proceden de la dinámica propia de cada relato, deben hacérsele evidentes al estudiantado, pues ello implica marcar un predominio de los textos propiamente tales, por sobre las categorías de estudio. 
La segunda consideración radica en la necesidad de tomar en cuenta siempre que, en el estudio de los textos literarios, entran en juego dos elementos básicos: por un lado, los contenidos, organizados en temas o espacios (punto al cual se hará referencia específica en el siguiente apartado), y la forma expresiva que ellos adoptan (forma que se puede explicar mediante las categorías de análisis que se asocian con este nivel de lectura). Los temas tratados en los textos literarios se inscriben dentro de las grandes preocupaciones del ser humano (la muerte, el dolor, la existencia de Dios, la política, el amor...), pero, a diferencia de la filosofía, adquieren una dimensión especial, debido a las formas expresivas que se hallan íntimamente vinculadas con las ideas. A esta estrecha relación entre tales instancias en el texto literario, se refiere Todorov (1991, p. 174) en los siguientes términos:

"Otro me argüirá: a ese precio la literatura no es más que la expresión de ideas que es lícito aprobar o contradecir. Pero semejante reacción presupone que la literatura es una unidad global. Ahora bien, justamente no lo es: es un juego formal de sus elementos y al mismo tiempo una instancia ideológica (así como muchas otras cosas); no es solamente búsqueda de la verdad, pero es eso también." (La cursiva no es del original.)

Así, una propuesta psicopedagógica de lectura de textos literarios debe contemplar ambos elementos: los de fondo y los de forma. No puede dejarse de lado ninguno de ellos, pues de su articulación depende, en cierta medida, lo específico de la literatura. Si se omite el análisis de las categorías propuestas, convendría más estudiar textos no literarios (noticias, textos científicos, editoriales...); a su vez, al olvidar los elementos de contenido podría caerse en un estudio literario mediante el cual se llegan a dominar ciertas categorías (narrador omnisciente, estilo culto, rima consonante, para citar unos cuantos ejemplos), las cuales resultarán, por sí solas, carentes de significado para los estudiantes.
Siguiendo el planteamiento de Todorov (1991), que le confiere a la literatura una intención fundamental de búsqueda de la verdad, se considera justificado plantear que, en el contacto con el texto literario, el lector principiante - no así quizá el lector especializado en la materia- se muestre más interesado por los temas de que trata, que por las diversas categorías de estudio a través de las que tales temáticas se manifiestan, por lo cual conviene tratar esos temas con más profundidad. En ese punto, se coincide totalmente con la posición de Todorov quien, en su propuesta de crítica dialógica, señala el profundo arraigo de la literatura en los problemas humanos:

"Desde hace doscientos años, los románticos y sus innumerables herederos nos han repetido a porfía que la literatura era un lenguaje que encuentra su fin en sí mismo. Ya es hora de volver (de regresar) a las evidencias que no han debido olvidarse: la literatura trata de la existencia humana, es un discurso, y por tanto peor para los que tienen miedo a las grandes palabras, orientado hacia la verdad y la moral. $L a$ literatura es un descubrimiento del hombre y de su mundo, decía Sartre; y tenía razón. No sería nada si no nos permitiera comprender mejor la vida."(P. 173. La cursiva no es del original.)

La importancia concedida a los temas de que tratan los textos literarios, conduce a una posición determinada en cuanto al tratamiento de los aspectos formales de la literatura en lo que se refiere a su aprendizaje por parte del alumno. Así, en relación con estos últimos aspectos, esta propuesta de aproximación psicopedagógica plantea la necesidad de que el análisis realizado en clase y que servirá como guía para la lectura que hacen los estudiantes, se centre principalmente en aquellos elementos verdaderamente significativos desde el punto de vista de la lectura interpretativa que se propone.

En suma, es importante que, desde una perspectiva psicopedagógica, se dirija el proceso de lectura de textos literarios centrándose en el significado o temas de los textos y que se busque relacionar esa temática con las categorías de análisis. 
Justamente Marina Müller (2001) plantea como objeto de la Psicopedagogía la búsqueda de procesos de aprendizaje dotados de sentido para los estudiantes; por ejemplo, un estudiante puede distinguir, desde un determinado nivel de comprensión lectora que, en los cuentos de Magón, el narrador utiliza un estilo culto, contrapuesto al lenguaje popular empleado por los personajes campesinos; sin embargo, la comprensión no será integral y, por ello, verdaderamente significativa para este lector, si no se asocia esta característica con la intención ideológica - según una determinada lectura de esta obra - de demostrar la superioridad de un grupo social sobre otro.

Al aludir, en este apartado, a la distinción entre aspectos de fondo y recursos expresivos, se ha adelantado en la reflexión de algunos puntos que, con base en la secuencia expositiva adoptada en este ensayo, corresponden más al nivel de lectura inferencial. Seguidamente se anotarán algunas recomendaciones relacionadas con este último.

\subsection{El nivel inferencial y la connotación}

El nivel de comprensión de lectura denominado inferencial o figurativo consiste en la elaboración de interpretaciones, conjeturas e hipótesis, por parte del lector, con base tanto en la información explícita e implícita como en sus propias intuiciones y experiencias personales (CR, MEP, 2005).

Con ello se ingresa de lleno en el plano connotativo. La connotación es un proceso en el cual se formulan sentidos secundarios, a partir de los contenidos explícitos. Estos segundos sentidos parten del establecimiento de relaciones a lo interno y a lo externo del texto, que siempre deben hallarse justificadas por algún indicio o "marca" textual. Obsérvese la definición de connotación que propone Roland Barthes (1987), con base en los postulados de Hjemslev:
"Para Hjemslev [...] la connotación es un sentido secundario, cuyo significante está constituido por un signo o un sistema de significación principal, que es la denotación: si E es la expresión, $\mathrm{C}$ el contenido y $\mathrm{R}$ la relación de los dos que funda el signo, la fórmula de la connotación es (ERC)RC." (P. 4)

"Definicionalmente, [la connotación] es una determinación, una relación, una anáfora, un rasgo que tiene el poder de referirse a menciones anteriores, ulteriores o exteriores, a otros lugares del texto (o de otro texto): no hay que restringir en nada esta relación, que puede ser designada de diversas maneras (función o indicio, por ejemplo), siempre que no se confunda connotación y asociación de ideas: ésta remite al sistema de un sujeto mientras que aquélla es una correlación inmanente al texto, a los textos, o si se prefiere, es una asociación operada por el textosujeto en el interior de su propio sistema." (P. 5)

En esta generación de segundos sentidos que se produce con la lectura connotativa, es necesario considerar los dos factores que, desde una perspectiva transaccional, intervienen activamente en todo proceso lector: por un lado, el texto, en este caso literario, con una serie de "marcas" que conducirán a realizar no una, sino varias posibles lecturas; y por otro lado, el sujeto que lee, en este caso un estudiante de tercer ciclo, quien con base en su experiencia previa con los textos literarios y con otros textos de la cultura, deberá interpretar esos indicios asignándoles un sentido que va más allá de la literalidad pura y simple. De tal manera, las posibilidades de interpretación dependerán tanto de los indicios textuales como del conocimiento del lector, que lo facultará para establecer relaciones entre aquellos y otros sentidos posibles.

Tómese como ejemplo el cuento de Julio Cortázar (2001) que se titula "Casa tomada". Es probable que un lector principiante encuentre, en este, una fuerte carga fantástica, que lo lleve a plantear la hipótesis de que las situaciones "extrañas" que se relatan son producidas por fantasmas que habitan la casa, y ello conduzca su lectura del texto. Sin embargo, otros lectores con un manejo de otro tipo de textos, podrían darle a este cuento una interpretación alegórica, relacionándolo con la historia 
de Adán y Eva y la expulsión del Paraíso; también existe la posibilidad de que haya interpretaciones de corte histórico-social, como que se trata de un retrato de la clase burguesa argentina, o bien, que en el texto se evidencia la amenaza del peronismo; mientras que otros lectores se atreverían a darle una interpretación psicoanalítica, al analizar la relación incestuosa de la pareja de hermanos. En una publicación dirigida a estudiantes de tercer ciclo se ha indicado, en relación con este cuento, lo siguiente:

“...[todas esas interpretaciones] pueden plantearse a partir de lo que dice el texto. Ello nos indica que el texto literario admite múltiples lecturas, pero ¡mucho cuidado! no admite cualquier lectura. La interpretación que le demos a una obra siempre tiene que estar respaldada por elementos tomados del texto mismo." (Méndez Anchía, 2002, p. 38)

No resulta coherente, por tanto, lo que se presenta en algunos materiales didácticos en los cuales, para el análisis de los textos literarios, se formula una lista de todos los espacios (o temas) posibles indicados en el programa de estudios (físico, ético, religioso, jurídico, educativo, económico, político, social, ecológico o psicológico) y se justifica la presencia de tales espacios por la simple mención de un elemento particular. Por ejemplo, la mención de la existencia de una escuela se usa como justificación para plantear que hay un espacio educativo, sin que necesariamente las marcas textuales estén remitiendo a una interpretación en que el tema de la educación sea relevante.

Retomando lo expuesto en el apartado anterior, lo que aquí se propone es que, en el estudio de la literatura con estudiantes de tercer ciclo, predomine la significación del texto literario mismo, con su pluralidad característica, y que para cada texto se estudien aquellas categorías que cumplan una función importante en la generación del significado, sea cual sea este. Lo mismo se aplica a la interpretación, donde las temáticas o espacios analizados deberán ser solamente aquellos que se hallen justificados por una serie de indicios que se articulan en una hipótesis de lectura específica; de otra forma, resultará difícil que los alumnos de tercer ciclo, que son lectores principiantes en el ámbito literario, comprendan en qué consiste la construcción de significados en este tipo de textos.

Hasta aquí se han señalado algunos lineamientos en torno a cómo articular los niveles de comprensión de lectura literal, de reorganización de lo explícito y figurativo, de acuerdo con ciertas características propias de la lectura literaria que se desprenden de lo planteado en el programa de estudios de Español del Ministerio de Educación Pública. Se ha indicado, entre otras cosas, que el lector realiza una lectura literal orientada por una labor de "muestreo" propia; que la reorganización de lo explícito debe inscribirse en una posible asignación de sentido del texto literario; que las categorías de análisis deben corresponderse con elementos significativos del texto, entendidos estos como aquellos temas o espacios que se derivan de la presencia de ciertos indicios textuales; todo ello tomando en cuenta que la lectura siempre se da por una búsqueda de sentido, la cual es realizada por el lector de acuerdo con sus experiencias previas y el conocimiento de otros textos.

Se ha planteado, hasta aquí, una estrategia de lectura coherente con ciertas demandas cognoscitivas del lector y con algunos criterios relativos a la especificidad del texto literario. Sin embargo, una propuesta psicopedagógica no puede limitarse a ello. Debe considerar también la función formadora de la lectura, entendida como aquella que fomenta una comprensión de la realidad propia del estudiante y del medio que lo circunda. A esta función se hará referencia en el apartado siguiente, dedicado a los niveles de comprensión de lectura evaluativo, apreciativo, aplicativo y recreativo, a los cuales es preciso reconocerles una importancia fundamental en la formación de los lectores adolescentes. 


\subsection{Los niveles evaluativo, apreciativo, aplicativo y recreativo: su aprovechamiento en la función formadora de la lectura}

Refiriéndose a los materiales diseñados para fomentar la lectura, Monson (1989) señala que deben incorporar las reacciones personales y críticas de los alumnos respecto de los textos. A esas reacciones personales, a través de las cuales es posible facilitar una participación más activa del lector en el tercer ciclo, se refieren los niveles evaluativo, apreciativo, aplicativo y recreativo de la comprensión lectora.

El nivel de comprensión evaluativo contempla la emisión de juicios, por parte del lector, a partir de diferentes criterios como la comparación entre sus vivencias, su saber y sus valores en relación con lo que plantea un texto. Suponen una actitud objetiva, mediante la que se analizan aspectos tales como cualidades, verosimilitud, probabilidad, aceptabilidad, actualidad y claridad de los textos (CR, MEP, 2005).

El nivel apreciativo, por su parte, abarca las respuestas emocionales ante lo planteado, trátese de contenidos, de aspectos psicológicos o estéticos. Puede comprender reacciones tales como miedo, pereza, simpatía, antipatía e identificación (CR, MEP, 2005).

En el nivel aplicativo y recreativo, la actividad lectora se centra en el empleo de la información del texto para aplicarla a condiciones reales o imaginarias. Supone la elaboración de otros textos creados por el lector, entendiendo textos en un sentido muy amplio, que abarca materiales escritos, dibujo, sonido, dramatización, juego e imaginación (CR, MEP, 2005).

En el ámbito específico de la lectura literaria, en esta última etapa del proceso se retoman con mayor énfasis la singularidad, intereses y criterios propios del lector, que han estado presentes desde el momento mismo en que en el nivel de lectura literal este ha utilizado estrategias de "muestreo", y se han acentuado en la práctica interpretativa, cuyo sentido depende, además de las marcas textuales, de las experiencias previas del lector con otros textos (literarios y culturales en general).

Lisa Block de Behar, en su libro Una retórica del silencio (1984), ha analizado esta circunstancia de la participación inevitable del lector en el proceso de lectura literaria:

"A fin de realizar su lectura, un lector depende de las opciones que le proporciona la historia general de la literatura, pero cada lector, a su vez, condiciona esa historia a su historia personal. Permaneciendo, la obra logra sustraerse a las contingencias históricas de las que parte y se aparta, pero la autonomía de su 'heterocosmos' no excluye que cada vez el lector intente remitirla a su historia: la de la obra y la suya propia. Prescinde de la historia por una parte, aunque por otra la historización es, por lo menos, doble. El lector se encuentra en la encrucijada de tantas circunstancias, fortuitas o arbitrarias, aleatorias o previsibles $y$, sin embargo, sucede que es en función de esas coordenadas problemáticas, sus tendencias e intereses, que trazará los rumbos de su lectura." (Pp. 69-70. La cursiva no es del original.)

En estos niveles, la lectura literaria puede contribuir, de una manera mucho más directa que en los anteriores, a articular los intereses, actitudes, reacciones y recreaciones de los estudiantes, mediante múltiples actividades productoras de nuevos textos. Obsérvese, en el siguiente ejemplo basado en "La Propia", de Magón (1998), cómo es posible articular informaciones procedentes del nivel reorganizador de lo explícito (características del movimiento literario en este caso), con acciones propias de los niveles aplicativo, evaluativo y recreativo, de manera tal que el proceso lector propuesto en las estrategias de trabajo en clase constituya una unidad de sentido:

Anote las características del Costumbrismo presentes en "La Propia". Luego observe un lugar que le sea familiar (su barrio o el colegio, por ejemplo), descríbalo detalladamente y juzgue alguna conducta que le parezca negativa. Por último, redacte un breve cuadro de costumbres, ial estilo de Magón! 
Para citar otro ejemplo, la lectura de un texto controversial como El Jaúl, de Max Jiménez (1995), puede dar pie a que los estudiantes reflexionen sobre el rumbo de la sociedad en que viven, en una actividad en que se aprovechan tanto habilidades procedentes del nivel literal y reorganizador de lo explícito, como la producción de nuevos textos mediante una técnica de expresión oral. La guía de lectura propuesta podría plantearse en estos términos:

Con base en sus reflexiones personales y a partir de la lectura de $E l$ Jaúl, de Max Jiménez, organice con sus compañeros de clase un debate sobre el siguiente tema: ¿Hacia dónde marcha Costa Rica: hacia la degradación, o hacia el mejoramiento?

Como puede verse, las respuestas emocionales ante la lectura, lo mismo que su aplicación a circunstancias de la historia del sujeto y las posibilidades de recreación del texto literario, que suelen menospreciarse en los estudios literarios profesionales, adquieren un papel protagónico en una propuesta psicopedagógica de comprensión lectora de textos literarios con estudiantes de tercer ciclo. En la tarea formadora en que participan los docentes en relación con estos alumnos, es tan importante que ellos realicen una interpretación sólida aplicando la connotación y de acuerdo con indicios textuales, como que puedan evaluar y sobre todo aplicar lo leído a su vida personal y a la comprensión de su entorno; de lo contrario, por coherente que fuera su manejo de las inferencias textuales y su dominio de las categorías de análisis literario, dicha tarea podría resultarles agotadora, como lo plantea Marc Soriano:

"Al no ligar el libro a la expresión propia del niño, al no usarlo para comunicar lo que realmente a él le interesa, la enseñanza le presenta el arte y la cultura como realidades exteriores, que no podrá adquirir sino mediante un esfuerzo desmesurado..." (1999, p. 270)

En efecto la lectura, y en particular la de textos literarios, puede cumplir múltiples funciones en el desarrollo de los niños y los jóvenes, entre las que está un aprovechamiento pedagógico que trasciende el estudio de categorías de análisis historicista y teórico-literarias, lo mismo que el desarrollo de habilidades lectoras propiamente tales, para abarcar una tarea formadora de los lectores. Esa formación no se limita a la transmisión de informaciones o a la construcción de conocimientos, sino que apela a la persona misma en lo más íntimo de su subjetividad; así la perfila Jorge Larrosa (1998, p. 19):

"Pensar la lectura como formación supone cancelar esa frontera entre lo que sabemos y lo que somos, entre lo que pasa (y que podemos conocer) y lo que nos pasa (como algo a lo que debemos atribuir un sentido en relación a nosotros mismos)."

Esa función formadora de la lectura ha recibido valiosos aportes de algunas corrientes psicoanalíticas, desde las cuales se ha planteado, por ejemplo, la identificación de los sujetos con los diversos personajes y situaciones de los textos literarios como una forma de descubrir el sentido de su propia vida (Bettelheim, 1988) y como una manera de desarrollar su inteligencia en la realidad (Dolto, 1997). Asimismo, la lectura y comentario de textos literarios abren canales comunicativos para explorar temas tales como los miedos, las pérdidas y la competencia, que afectan tanto a los adolescentes (Grasso Fitzpatrick, 2001).

Véanse, a continuación, dos posibilidades de ejercicios —uno con base en "Vuelo supremo", de Julián Marchena (1965), y otro basado en La loca de Gandoca, de Anacristina Rossi (2001) - que conjugan esa apertura de canales comunicativos y de desarrollo de la inteligencia del sujeto en la realidad, con actividades propias de los niveles de lectura evaluativo, apreciativo, aplicativo y recreativo:

Redacte un párrafo sobre las cosas que usted quiere hacer en la vida. Empiece igual que el poema "Vuelo supremo”, de Julián Marchena: "Quiero...”

¿Qué actitud adoptó Daniela, la protagonista de $L a$ loca de Gandoca, ante la destrucción del Refugio y 
la enfermedad de su compañero? Ensaye variaciones para el texto: ¿Qué habría pasado si la actitud de Daniela hubiera sido la de guardar silencio? ¿Qué habría pasado si su actitud hubiera sido la de ingerir bebidas alcohólicas? ¿Qué habría hecho usted ante una situación como esta?

Justamente en esta etapa crítica de la adolescencia, por la que atraviesan los estudiantes del tercer ciclo, resulta provechoso que, en el ámbito escolar, los sujetos tengan un contacto con la literatura que los ayude a desarrollar su inteligencia en la realidad, a comprender el mundo y a comprenderse ellos mismos, fomentando su conocimiento emocional. De tal manera, el abordaje historicista y basado en categorías teórico-literarias que ha predominado en el planteamiento curricular de los temas literarios en la enseñanza media costarricense, producto del predominio de un enfoque academicista, se enriquece con la posibilidad de enfatizar en la formación y transformación personal que el contacto con los textos literarios podría estar generando en el estudiante, buscando tanto la creación de "buenos" (acertados) lectores como la formación de sujetos amantes de la lectura. Así lo plantea Soriano (1999, p. 272):

“...el fin de la enseñanza es y seguirá siendo atender al interés del niño; se trata no sólo de que aprenda a leer sino de que ame la lectura. Ya que el libro, en este universo de imágenes obsesivas que es el nuestro, resulta un instrumento de reflexión y de reencuentro de uno mismo realmente irremplazable y cada vez más necesario para la adquisición del espíritu crítico."

\section{Conclusiones}

Uno de los principales desafíos que enfrenta el sistema educativo costarricense es, según el Programa Estado de la Nación en Desarrollo Humano Sostenible (2005), el de responder a la diversidad, promoviendo competencias básicas y proveyendo una formación integral; "además [señala el informe Estado de la Educación] se debe buscar que el proceso educativo sea más estimulante para retener a los adolescentes que hoy opinan que la educación es poco atractiva y a veces hasta 'carente de sentido" (p. 15).

En el año 2004, un 11,6\% de estudiantes desertaron de la secundaria, y uno de los motivos que se aducen, junto con los problemas económicos, es justamente la falta de motivación (Programa Estado de la Nación en Desarrollo Humano Sostenible, 2005). De ahí la necesidad de dotar de sentido las prácticas educativas, mejorando "la pertinencia de la enseñanza secundaria para hacerla más actual e interesante, ya que una de las principales causas de deserción es el desinterés de las y los estudiantes" (p. 16).

Urge, por lo tanto, que los contenidos resulten significativos para los estudiantes, con mucha más razón si se trata de textos literarios. Un enfoque de enseñanza de la literatura que se concentre en el dominio de ciertas categorías especializadas, quizá no resulte lo suficientemente motivador para el alumnado. Si se pretende que la enseñanza de la literatura apele directamente a los estudiantes, es necesario promover los procesos de formación y transformación personal que el contacto con el texto literario podría estar generando en ellos.

Se afirma, así, la importancia de una propuesta psicopedagógica de aproximación a la lectura de textos literarios en la enseñanza media cuyo énfasis esté en el sujeto adolescente y en ciertas estrategias de trabajo con textos literarios que generen procesos de conocimiento propio, lo cual habrá de redundar en un mejor desempeño del estudiante en su realidad.

En este ensayo, se ha propuesto un marco de referencia sobre los procesos lectores en relación con los textos literarios cuya finalidad consiste en favorecer una aproximación psicopedagógica a la literatura, que contemple tanto las categorías de análisis específicas que se proponen en el programa de estudios, como los procesos cognitivos asociados con los distintos niveles de comprensión de lectura que también se citan en dicho programa, y que a la vez 
plantee la posibilidad de enfatizar en la literatura como formadora de los estudiantes en lo que se refiere a su vida personal y a su realidad circundante.

Se parte de la premisa de que todo proceso de lectura se rige por una búsqueda de sentido, es decir, que el lector va tratando de encontrar un significado conforme va descifrando el texto, situación que se torna más compleja debido a la pluralidad del texto literario.

Algunas recomendaciones que se desprenden de esta propuesta son las siguientes:

a) Debe considerarse siempre que la lectura de datos explícitos depende del proceso particular de "muestreo" efectuado por cada lector, proceso que se inserta en un trabajo de transacción texto-lector.

b) Habilidades tales como el análisis, la síntesis, la esquematización, la paráfrasis y la jerarquización, necesarias para organizar las informaciones que darán pie a la formulación de una lectura interpretativa, se hallan dentro de un proceso de asignación de un sentido posible al texto literario.

c) Para evitar un estudio descontextualizado de las categorías predominantes en cada género y de las características de los diversos movimientos, es necesario efectuar, por un lado, una aproximación flexible a los textos literarios, respetando su variedad, sus diferencias y semejanzas con otros textos, no leyéndolos a todos como si fueran uno solo; $y$, por otro lado, contemplar tanto los elementos de fondo como los de forma, tratando con más profundidad los temas que presenta el texto literario.

d) Es preciso tomar en cuenta la experiencia previa del sujeto lector con los textos literarios y con otros textos de la cultura, pues con base en ella interpreta los indicios textuales asignándoles un sentido que trasciende el plano literal.

e) Es necesario aprovechar los niveles evaluativo, apreciativo, aplicativo y recreativo para desarrollar una "inteligencia en la realidad", que lleve al estudiante a relacionar el texto literario con su vida misma y su entorno; de esta manera, comprenderá mejor la realidad en que se desenvuelve, con lo cual la lectura será enteramente formadora.

Las pérdidas, las relaciones en la familia y con otros adultos importantes, la necesidad (o el temor) de salir del hogar, las decisiones acerca de su vida futura, los miedos (producto de un sentido de identidad tambaleante) y, por qué no, hasta el fracaso escolar (con sus implicaciones en la vida personal y familiar): estos temas asociados a las diversas transformaciones que sufre la persona en esta etapa de la vida - denominada por Dolto (2004) como el "complejo de la langosta", para referirse al periodo en que esta pierde su concha y se halla en un estado de vulnerabilidad pasajera-, podrían formar parte de las discusiones y reflexiones que, a propósito de la literatura, se entablen en el salón de clase.

Si se contempla el desarrollo integral de las habilidades de comprensión lectora de textos literarios tomando como eje al estudiante - que constituye el otro elemento del proceso transaccional de la lectura-, se le estará dando un enfoque más integral al currículo del tercer ciclo, justamente en una etapa de la vida del estudiante que se caracteriza por una preocupación por su vida personal, por la toma de decisiones importantes y por un contacto crítico con su medio circundante. 


\section{Referencias bibliográficas}

Barthes, Roland (1987). S/Z. México: Siglo XXI.

Bettelheim, Bruno (1988). Psicoanálisis de los cuentos de hadas. México D. F.: Grijalbo, trad. de Silvia Furió.

Block de Behar, Lisa (1984). Una retórica del silencio. Funciones del lector y los procedimientos de la lectura literaria. México: Siglo XxI.

Bolaños, Gerardo y Molina, Zaida (1990). Introducción al currículo. San José: EUNED.

Cortázar, Julio (2001). Los relatos 3 : Pasajes. Madrid: Alianza.

Costa Rica, Ministerio de Educación Pública. Programa de estudios de Español, Tercer Ciclo (actualizado al 2005). Recuperado el 17 de octubre del 2005, de http://www.mep.go.cr/ DescargasHTML/Curricular/doc/ EspañolIIICiclo.doc

Dolto, Françoise (2004). La causa de los adolescentes. Barcelona: Paidós, trad. de R. M. Bassols.

Dolto, Françoise (1997). Niño deseado, niño feliz. Barcelona: Paidós, trad. de Alfredo Báez.

Fallas, Carlos Luis (1995). Marcos Ramírez. San José: Editorial Costa Rica, segunda edición.

Goodman, Kenneth S. (1996). "El proceso de lectura: consideraciones a través de las lenguas y del desarrollo". Ferreiro, Emilia y Gómez Palacio, Margarita (Eds.). Nuevas perspectivas sobre los procesos de lectura $y$ escritura. México: Siglo XXI. Pp. $13-28$
Grasso-Fitzpatrick, Jean (2001). Cuentos para leer en familia. Historias que favorecen el desarrollo sano de los niños. Barcelona: Paidós.

Jiménez, Max (1995). El Jaúl. San José: Editorial Costa Rica.

Larrosa, Jorge (1998). La experiencia de la lectura. Estudios sobre literatura y formación. Barcelona: Laertes, segunda edición.

Magón (seudónimo, 1998). Cuentos. San José: Editorial Costa Rica.

Marchena, Julián (1965). Alas en fuga. San José: Editorial de la Universidad de Costa Rica.

Méndez Anchía, Silvia (2002). "Casa tomada”. Fernández Lobo, Mario. Textos de lectura y comentarios para noveno año. San José: Fernández-Arce. Pp. 32-47.

Méndez Anchía, Silvia (2000). "La mediación docente en la comprensión de lectura de textos literarios". Revista Educación. UCR. Vol. 24, núm. 1. Pp. 89-105.

Monson, Diane L. (1989). "Rastreando en un libro y más allá de él: las reacciones ante la literatura”. Monson, Diane L. y Mc. Clenatah, DayAnn K. (Eds.). Crear lectores activos. Propuestas para los padres, maestros y bibliotecarios. Madrid: Visor Distribuciones.

Müller, Marina (2001). Aprender para ser. Principios de Psicopedagogía Clínica. Buenos Aires: Bonum, tercera edición.

Programa Estado de la Nación en Desarrollo Humano Sostenible (2005). Estado de la Educación Costarricense. San José: El Programa. 
Rossi, Anacristina (2001). La loca de Gandoca. San José: Legado.

Sánchez, Víctor; Rojas, Marta; Víquez, Alí (1997). Español 8: guía didáctica. San José: Editorial de la Universidad de Costa Rica, PROMECE, Ministerio de Educación Pública.
Soriano, Marc (1999). La literatura para niños y jóvenes. Guía de exploración de sus grandes temas. Buenos Aires: Ediciones Colihue, trad. de Graciela Montes.

Todorov, Tzvetan (1991). Crítica de la crítica. Una novela de aprendizaje. Caracas: Monte Ávila Editores, segunda edición, trad. de José Sánchez Lecuna. 
